\title{
Arsenic Removal from Water by Green Synthesized Magnetic Nanoparticles
}

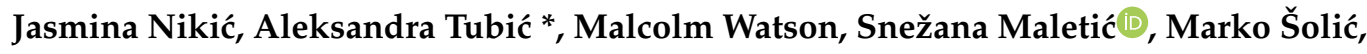 \\ Tatjana Majkić and Jasmina Agbaba
}

Department of Chemistry, Biochemistry and Environmental Protection, Faculty of Sciences, University of Novi Sad, Trg Dositeja Obradovića 3, 21000 Novi Sad, Serbia; jasmina.nikic@dh.uns.ac.rs (J.N.); malcolm.watson@dh.uns.ac.rs (M.W.); snezana.maletic@dh.uns.ac.rs (S.M.); marko.solic@dh.uns.ac.rs (M.Š.); tatjana.majkic@dh.uns.ac.rs (T.M.); jasmina.agbaba@dh.uns.ac.rs (J.A.)

* Correspondence: aleksandra.tubic@dh.uns.ac.rs

Received: 30 September 2019; Accepted: 25 November 2019; Published: 28 November 2019

\begin{abstract}
Magnetite nanoparticles were synthesized by a simple and ecofriendly method using onion peel (MNp-OP) and corn silk extract (MNp-CS), in order to develop new low-cost adsorbents for arsenic removal from groundwater. As a point of comparison, magnetite nanoparticles were also synthesized with a conventional chemical process (MNp-CO). The antioxidant potential of onion peel and corn silk extracts was determined using ferric reducing antioxidant power (FRAP) and free radical (DPPH) scavenging assays, including the total phenolics, flavonoids and tannins contents. The synthesized magnetite nanoparticles were characterised using different techniques (Scanning electron microscope/Energy dispersive spectroscopy (SEM/EDS), X-ray diffraction (XRD), Fourier-transform infrared spectroscopy (FTIR) and Brunauer-Emmett-Teller (BET) surface area analyzer). The adsorption capacity of $\mathrm{MNp}$-OP and $\mathrm{MNp}$-CS and the arsenic removal mechanism of these novel adsorbents was investigated through kinetic and equilibrium experiments and their corresponding mathematical models. Characterisation of MNp-OP and MNp-CS shows high BET specific surface areas of $243 \mathrm{~m}^{2} / \mathrm{g}$ and $261 \mathrm{~m}^{2} / \mathrm{g}$, respectively. XRD and FTIR analysis confirmed the formation and presence of magnetite nanoparticles. The arsenic adsorption mechanism on $\mathrm{MNp}-\mathrm{OP}, \mathrm{MNp}-\mathrm{CS}$ and $\mathrm{MNp}-\mathrm{CO}$ involves chemisorption, intraparticle and external diffusion. Maximal adsorption capacities of MNp-OP, MNp-CS and MNp-CO were 1.86, 2.79, and $1.30 \mathrm{mg} / \mathrm{g}$ respectively. The green synthesis applied using onion peel and corn silk extracts was cost effective and environmentally friendly, and results in adsorbents with a high capacity for arsenic and magnetic properties, making them a very promising alternative approach in the treatment of arsenic contaminated groundwater.
\end{abstract}

Keywords: magnetite nanoparticles; onion peel; corn silk; arsenic; adsorption; groundwater

\section{Introduction}

The presence of arsenic in groundwater, either from anthropogenic or natural sources, is a serious problem in many different parts of the world. Millions of people, mostly in rural and developing countries, are exposed to high levels of arsenic via the intake of arsenic rich groundwater [1]. The main concerns related to arsenic in groundwater are its high toxicity and carcinogenicity, since long-term exposure to arsenic has been associated with cancer (skin, lungs, urinary tract, kidneys and liver) and other various noncancerous diseases [2]. In order to minimize and reduce the adverse health effects, the World Health Organization (WHO) recommends a maximum allowable concentration (MAC) for arsenic in drinking water of $10 \mu \mathrm{g} / \mathrm{L}$ [3]. 
Various technologies have been employed for arsenic removal from groundwater including coagulation, membrane separation, ion exchange and adsorption [4]. Among these techniques, adsorption offers many advantages including simple and stable operation, easy handling of waste, absence of added reagents, compact facilities, and generally lower operation costs [5-8].

Many synthetic and natural adsorbents have been developed and applied for arsenic removal, however in recent years, iron nanoparticles (INPs) have been the most interesting novel materials, due to their unique physicochemical properties (small particle size, high surface area, high magnetism, low toxicity) and their strong affinity for arsenic species [9-12]. INPs can be classified into three major groups namely:

(1) iron oxide nanoparticles (IONs) (i.e., magnetite; $\mathrm{Fe}_{3} \mathrm{O}_{4}$, hematite: $\alpha-\mathrm{Fe}_{2} \mathrm{O}_{3}$, maghemite; $\gamma$ - $\mathrm{Fe}_{2} \mathrm{O}_{3}$ ),

(2) iron oxide hydroxide $(\mathrm{FeOOH})$ nanoparticles and

(3) zero-valent iron (ZVI) nanoparticles.

Among the iron oxide nanoparticles, magnetite $\left(\mathrm{Fe}_{3} \mathrm{O}_{4}\right)$ and maghemite $\left(\gamma-\mathrm{Fe}_{2} \mathrm{O}_{3}\right)$ nanoparticles, have attracted a lot of attention for applications with arsenic contaminated waters [13-16]. Their ease of fabrication and high adsorption capacities for arsenic and super-paramagnetic properties allow for their easy separation from water, make them popular candidates for remediation of arsenic contaminated groundwaters.

Different methods have been reported for the synthesis of magnetic nanoparticles such as sol-gel process [16], electrical wire explosion (EWE) [13], hydrothermal synthesis [17], coprecipitation [18], etc. These methods require toxic solvents, high energy consumption and/or generate hazardous by-products. In contrast to these chemical and physical methods, the green synthesis of nanoparticles has been proposed as a cost-effective environmentally friendly and promising approach [19]. Biogenic or green synthesis of magnetic nanoparticles includes the use of plants, algae, and different microorganisms (yeast, fungi, diatoms, and bacteria), with plant-mediated synthesis of magnetite nanoparticles being the most investigated. Different parts of plants can be applied for the synthesis of magnetic nanoparticles; however, most researchers apply various leaf extracts [20-25]. In general, the extracts obtained from plants contain a variety of phytochemicals (polyphenolics, flavonoid, tannins etc.) and various types of proteins, enzymes, polysaccharides and alcoholic compounds which can act as natural sources for reducing and capping agents in a one-pot synthesis reaction. Such an approach eliminates multistep synthesis practice problems and the costs of chemical reagents. Moreover, the use of plant residues from non-food sources (which would otherwise be waste materials) as a feedstock for green synthesis reactions reduces production costs and further contributes to sustainability.

To date, there is no literature relating to the green synthesis of magnetite nanoparticles using extracts obtained from onion peel and corn silk, or their application on arsenic remediation.

Onion (Allium cepa L.) is one of the most frequently consumed vegetables, and its production increases every day due to increasing consumer demand. Simultaneously, huge amounts of waste are produced from different parts of the onion, which affect the environment in various ways. Hence, proper use as well as disposal of this waste is important from an environmental aspect [26]. The concentrations of total phenols, flavonoids, flavonols and other antioxidants are higher in the onion peel than in the edible portion of the onion [27-30]. This waste therefore has great promise as a natural reductant in the one-pot synthesis of magnetic nanoparticles.

Corn silk, the female flower stigma of maize (Zea mays L.), is a yellow silky strand found on the top of corn fruit. Corn silk is a by-product obtained from corn production such as food, processed food and animal feed, and is discarded as waste together with other parts of corn such as the cob and husk [31]. Like onion peel, corn silk contains various components, including protein, vitamins, carbohydrates, $\mathrm{Ca}, \mathrm{K}, \mathrm{Mg}$, sitosterol, stigmasterol, alkaloids, saponins, tannins and flavonoids (maysin, methoxymaysin, apimaysin, and luteolin derivatives). Moreover, it is a good source of polyphenol compounds, which are strong antioxidants [32,33]. Corn silk is used in traditional medicine to treat 
many diseases $[34,35]$, but despite its medicinal properties, it is still not used in the pharmaceutical industry and is treated as a waste material.

Thus, in this study magnetite nanoparticles were synthesized for the first time in a one-step process using extract obtained from onion shell (Mag-OS) and corn silk (Mag-CS). These novel adsorbents were characterized by different techniques (SEM/EDS, XRD, FTIR, BET) and further applied for arsenic removal from groundwater. In order to compare efficiency of the green synthesis, as well arsenic adsorption capacities, magnetic nanoparticles were also synthesized by conventional chemical coprecipitation method (MNp-CO), the most common fabrication pathway for this material.

\section{Materials and Methods}

\subsection{Green Synthesis of Magnetic Nanoparticles}

\subsubsection{Preparation of Onion Peel and Corn Silk Extracts}

Onion peels (OP) and corn silk (CS) were collected from locally grown produce (Dutch yellow onions and NS 6010 Hybrid corn, both from NS Seme, Novi Sad). The collected materials were washed several times with distilled water to remove impurities, dried at ambient temperature, then cut into small pieces. Ten $\mathrm{g}$ of CS/OP were weighed and transferred to a $500 \mathrm{~mL}$ beaker, to which $300 \mathrm{~mL}$ of distilled water was added. The beaker was then placed in a shaker bath at $30^{\circ} \mathrm{C}$ for $1 \mathrm{~h}$. After shaking, the solution was filtered with a Büchner Vacuum Filtration Funnel and the filtrate was used for magnetite nanoparticles production.

\subsubsection{Preparation of Magnetite Nanoparticles}

The magnetic nanoparticles were synthesized by green precipitation method without addition of a chemical reducing agent. In green synthesis, the plant extracts act as chemical reducing agents while sodium acetate acts as an electrostatic stabilizing agent for the produced $\mathrm{Fe}_{3} \mathrm{O}_{4}$ nanoparticles [36]. In the reaction procedure, $2.16 \mathrm{~g}$ of $\mathrm{FeCl}_{3} \cdot 6 \mathrm{H}_{2} \mathrm{O}$ and $6.56 \mathrm{~g}$ of sodium acetate was dissolved in $40 \mathrm{~mL}$ of corn silk/onion peel extract. The suspension was placed under vigorous stirring for $1 \mathrm{~h}$ at $80^{\circ} \mathrm{C}$, and the resulting precipitate centrifuged and washed several times with distilled water. The obtained magnetic nanoparticles were dried in an oven at $105^{\circ} \mathrm{C}$. The synthesized magnetic nanoparticles were denoted as MNp-CS and MNp-OP.

\subsection{Synthesis of Magnetic Nanoparticles by Coprecipitation Methods}

In order to compare the efficiency of the green synthesis method and the adsorption capacity of the green nanoparticles obtained (MNp-CS and $\mathrm{MNp}-\mathrm{OP}$ ), magnetic nanoparticles were also synthesized via the chemical coprecipitation method using $\mathrm{Fe}^{3+}$ and $\mathrm{Fe}^{2+}$ salts at a molar ratio of 2:1. $2.50 \mathrm{~g}$ of $\mathrm{FeCl}_{3} \cdot 6 \mathrm{H}_{2} \mathrm{O}$ and $1.21 \mathrm{~g} \mathrm{FeSO}_{4} \cdot 7 \mathrm{H}_{2} \mathrm{O}$ were dissolved in $40 \mathrm{~mL}$ of deionized water in a $200 \mathrm{~mL}$ glass beaker. Two $\mathrm{M} \mathrm{NaOH}$ solution was added dropwise until the mixture reached $\mathrm{pH} 9$ and a black precipitate developed. The synthesized $\mathrm{MNp}-\mathrm{CO}$ were then separated from the suspension by external magnet and washed repeatedly with deionised water until a supernatant of neutral $\mathrm{pH}$ was obtained.

\subsection{Characteristion of Plant Extracts}

Total phenolics in the plant extract were determined by Folin-Ciocalteu reagent (FC), as previously described [37]. The total phenol content (TPC) was expressed as mg of gallic acid equivalents (GAE) per g dry weight $(\mathrm{dw})$ of extracts. The tannin content was determined using insoluble polyvinyl polypirrolidone, which binds the tannins. The total tannin content (TTC) was expressed as mg of catechin equivalents (CE) per g dry weight ( $\mathrm{dw}$ ) of extracts. The total content of flavonoids (TFC) was determined by using the aluminium chloride colorimetric method as previously described. The total content of flavonoids was expressed as mg of quercetin equivalents (QE) per g dry weight (dw) of 
extracts. The antioxidant potential of plant extracts was determined using tests related to free radical $\left(\mathrm{DPPH}^{\bullet}\right)$ scavenging.

Reducing power was measured by Ferric Reducing Antioxidant Power (FRAP) assay according to the previously described procedure [38]. Reducing power were expressed as mmol of trolox equivalents (TE) per g dry weight (dw) of extracts.

\subsection{Characterisation of Magnetite Nanoparticles}

The specific surface area of the magnetic nanoparticles was measured by nitrogen adsorption using the Brunauer-Emmett-Teller (BET) method with a Autosorb TMiQ surface area analyzer (Quantachrome, Boynton Beach, FL, USA). Mesopore and micropore volumes were determined using the Barett-Joyner-Halender (BJH) method using desorption isotherm, and $t$-test method, respectively. The surface morphology, microstructure and elemental composition of the magnetic nanoparticles were examined using scanning electron microscopy combined with energy dispersive $\mathrm{X}$-ray spectroscopy (SEM-EDX) (Hitachi TM3030, Japan). X-ray diffraction (XRD) patterns were obtained on Philips PW automated X-ray powder diffractometer (USA). Fourier transform infrared (FTIR) spectra of magnetic nanoparticles were recorded by infrared spectrophotometer (FTIR Nexus 670, Thermonicolet, USA). The point of zero charge $\left(\mathrm{pH}_{\mathrm{pzc}}\right)$ of the magnetic nanoparticles was determined according to the method described by Zhang et al. [39]

\subsection{Adsorption Experiments}

Adsorption experiments were conducted with groundwater samples taken from Višnjićevo (a settlement located in the Autonomous Province of Vojvodina, Serbia). The characteristics of the groundwater are given in Table 1. Measurement uncertainties are expressed as the standard deviations of 10 separate measurements. For the kinetics experiments, $20 \mathrm{~mL}$ water samples were added to $40 \mathrm{~mL}$ glass bottles containing $10 \mathrm{mg}$ of synthesized magnetic nanoparticles (MNp-CS, MNp-OP and $\mathrm{MNp}-\mathrm{CO})$. The suspensions were shaken on an orbital shaker $\left(180 \mathrm{rpm}, 22^{\circ} \mathrm{C}\right)$ for certain periods of time $(1,2,4,6,9,12,18,24 \mathrm{~h})$ and afterwards the supernatants were separated from the adsorbents using an external magnet. Residual arsenic concentrations in the samples were analyzed by inductively coupled plasma mass spectrometry (ICP-MS) as explained below. Equilibrium experiments were conducted with different sorbent doses $(0.01-0.1 \mathrm{~g})$ in the same manner as the kinetic experiments.

Table 1. Characteristics of the investigated groundwater.

\begin{tabular}{|c|c|}
\hline Parameter & Value $\pm s d^{a}$ \\
\hline $\mathrm{pH}$ & $8.05 \pm 0.15$ \\
\hline Conductivity $(\mu \mathrm{s} / \mathrm{cm})$ & $669 \pm 14.3$ \\
\hline Alkalinity (mmol/L) & $6.93 \pm 0.37$ \\
\hline Hardness $\left(\mathrm{mg} \mathrm{CaCO}_{3} / \mathrm{L}\right)$ & $133 \pm 48.3$ \\
\hline Total arsenic $(\mu \mathrm{g} / \mathrm{L})$ & $126 \pm 8.97$ \\
\hline Arsenic (III) & $98 \pm 12$ \\
\hline Arsenic (V) & $18 \pm 2.5$ \\
\hline $\mathrm{Fe}(\mu \mathrm{g} / \mathrm{L})$ & $20.2 \pm 25.8$ \\
\hline TOC (mgC/L) & $2.40 \pm 0.71$ \\
\hline $\mathrm{DOC}(\mathrm{mgC} / \mathrm{L})$ & $2.12 \pm 0.51$ \\
\hline Phosphate $\left(\mathrm{mgPO}_{4} / \mathrm{L}\right)$ & $1.33 \pm 0.05$ \\
\hline Chloride $(\mathrm{mgCl} / \mathrm{L})$ & $17.7 \pm 1.36$ \\
\hline Ammonium (mgN/L) & $0.15 \pm 0.10$ \\
\hline Sulfate $\left(\mathrm{mgSO}_{4} / \mathrm{L}\right)$ & $20.3 \pm 12.2$ \\
\hline
\end{tabular}

${ }^{a}$ sd-standard deviation, based on 10 measurements. 
The amount of arsenic adsorbed by a unit mass of adsorbent was calculated using the following equation:

$$
q_{e}=\frac{\left(C_{0}-C_{e}\right) V}{m}
$$

where $C_{0}$ and $C_{e}$ are the initial and equilibrium concentrations in solution $(\mathrm{mg} / \mathrm{L}) . V$ is the volume of solutions $(\mathrm{L})$ and $\mathrm{m}$ the mass of sorbent applied during the experiment $(\mathrm{g})$.

Different kinetic models (pseudo-first order, pseudo-second order model, Elovich, Weber-Morris and Boyd model) [40] were used to fit the kinetic experimental data while the Langmuir, Freundlich, Dubinin-Radushkevich and Tempkin isotherm [41] were applied for modelling equilibrium experimental data. The parameters of these models were determined by nonlinear fitting of the data using Origin 8.0 software (OriginLab Corporation, Northampton, MA, USA).

\subsection{Analytical Methods}

pH measurements were carried out using an InoLab pH/ION 735 instrument (WTW, Austria). Total arsenic concentrations were analyzed by ICPMS (7700 Series, Agilent Technologies, Tokyo, Japan) and arsenic speciation analyses were carried out on the same system coupled with high performance liquid chromatography (1260 Infinity, Agilent Technologies, Germany) [42,43]. Water alkalinity (pand m-alkalinity) was measured by titration with a standard solution of $\mathrm{HCl}$ according to Standard Methods [44]. The concentration of orthophosphate was determined according to the official Serbian translation of a method published by the International Organization for Standardization (SRPS EN ISO 6878: 2008) [45]. Concentration of chloride and ammonium was determined according to methods SRPS ISO 9297/1:2007 and SRPS ISO 5664:1992, respectively [46,47]. Dissolved organic carbon (DOC) in groundwater was analysed after filtration through a $0.45 \mu \mathrm{m}$ membrane filter on an LiquiTOCII (Elementar, Germany), using Pt catalysed combustion at $850{ }^{\circ} \mathrm{C}$ to oxidize the carbon, in accordance with standard method SPRS ISO 8245:2007 [48].

\section{Results and Discussion}

\subsection{Characterization of Magnetic Nanoparticles}

The addition of $\mathrm{FeCl}_{3}$ to the $\mathrm{OP}$ and $\mathrm{CS}$ extracts initiated the formation of magnetite nanoparticles $\mathrm{MNp}-\mathrm{OP}$ and $\mathrm{MNp}-\mathrm{CS}$. The surface morphology, as well as the qualitative and semiquantitative composition of the surface of these nanoparticles, was investigated by SEM/EDS analysis, as shown in Figure 1. The magnetite nanoparticles $(\mathrm{MNp}-\mathrm{CO})$ synthesized for the sake of comparison by conventional coprecipitation method is also shown.

It can be seen that the surfaces of all three materials are rough and contain a large number of particles that are irregular in shape and size. A large number of aggregated particles on the surface of these materials could be attributed to nanostructures and magnetic properties, which contribute a tendency for agglomeration and aggregation.

EDS analysis of MNp-OP showed iron and oxygen weights of $57.1 \%$ and $40.3 \%$, respectively. Similarly, MNp-CS contained $55.6 \% \mathrm{Fe}$ and $40.9 \% \mathrm{O}$. Trace amounts of $\mathrm{Cl}$ and $\mathrm{C}$ were found on the surface of both materials $(<2 \%)$. As with MNp-OP and MNp-CS, EDS analysis of MNp-CO showed a molar ratio of $\mathrm{Fe}: \mathrm{O}$ of $41.7 \%$ to $43.2 \%$. In general, the presence of $\mathrm{Fe}$ and $\mathrm{O}$ peaks in the surface of these materials confirms the formation of iron oxide. The presence of carbon can be attributed either to polyphenols or other phytochemical compounds or $\mathrm{CO}_{2}$ from air. The traces of $\mathrm{Cl}$ come from the $\mathrm{FeCl}_{3}$ precursor.

The phase identification and crystalline structures of the nanoparticles was characterized by X-ray powder diffraction. The $\mathrm{X}$-ray diffraction patterns of $\mathrm{MNp}-\mathrm{OP}, \mathrm{MNp}-\mathrm{CS}$ and $\mathrm{MNp}-\mathrm{CO}$ are presented in Figure 2. 

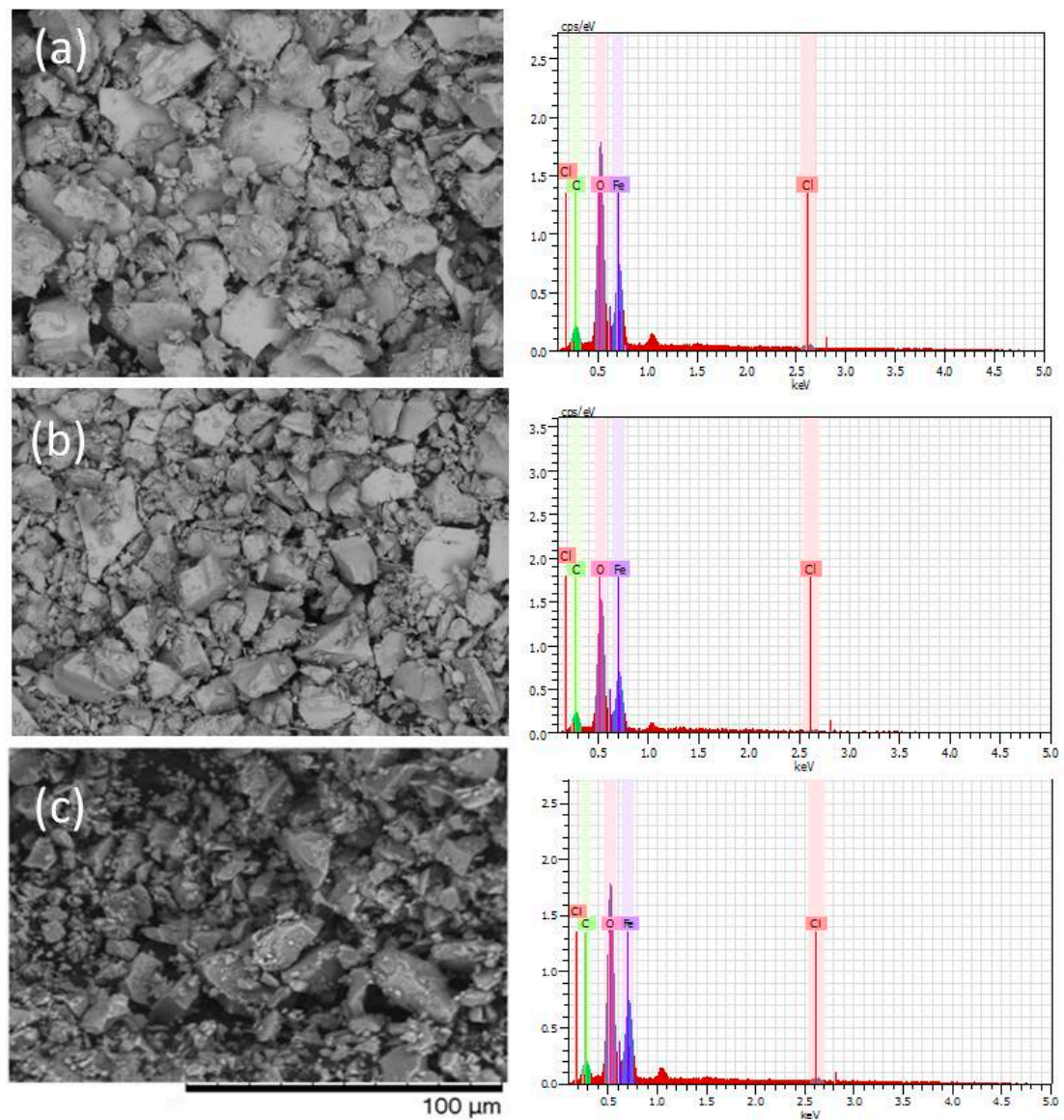

Figure 1. Scanning electron microscope (SEM) and energy-dispersive spectroscopy (EDS) images of (a) $\mathrm{MNp}-\mathrm{OP}$ (b) MNp-CS (c) MNp-CO.

(a)

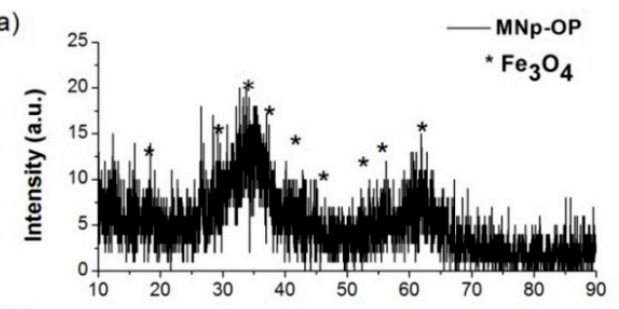

(b)
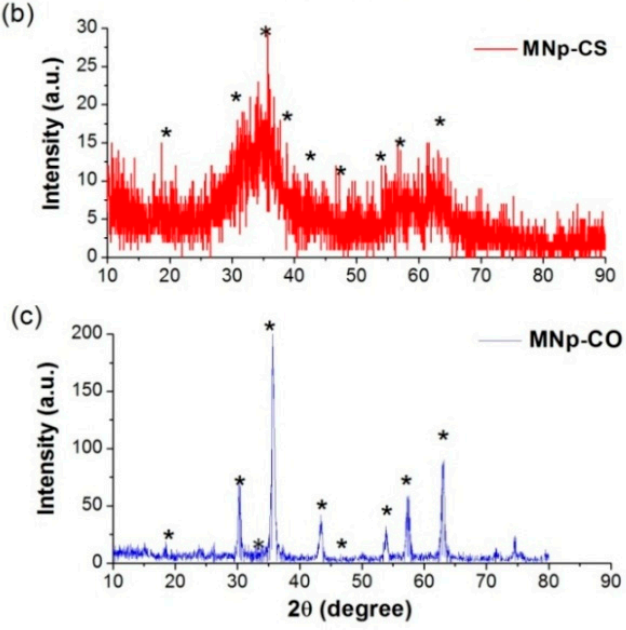

Figure 2. X-ray diffraction (XRD) patterns of (a) MNp-OP (b) MNp-CS and (c) MNp-CS. 
XRD patterns show that all diffraction peaks at $2 \theta=18.7,30.4,35.5,37.7,43.8,47.3,54.2,56.8$ and 62.5, show good matches with crystal planes of magnetite at (111), (220), (311), (222), (400), (331), (422), (511) and (440). Additionally, it may be noted that the peaks in XRD patterns of these materials were broad with low intensity, indicating nanosized particles $[25,36,49]$. The average particle sizes of the synthesized MNp-OP, MNp-CS and MNp-CO, which were calculated using the Debye-Scherrer equation [50] were found to be $26 \mathrm{~nm}, 28 \mathrm{~nm}$ and $12 \mathrm{~nm}$, respectively. Thus, the XRD patterns indicate that the magnetic nanoparticles were successfully synthesized using the green method.

The magnetic nanoparticles were also analyzed by FTIR spectroscopy. The corresponding FTIR spectra of MNp-OP, MNp-CS and MNp-CO are presented in Figure 3.

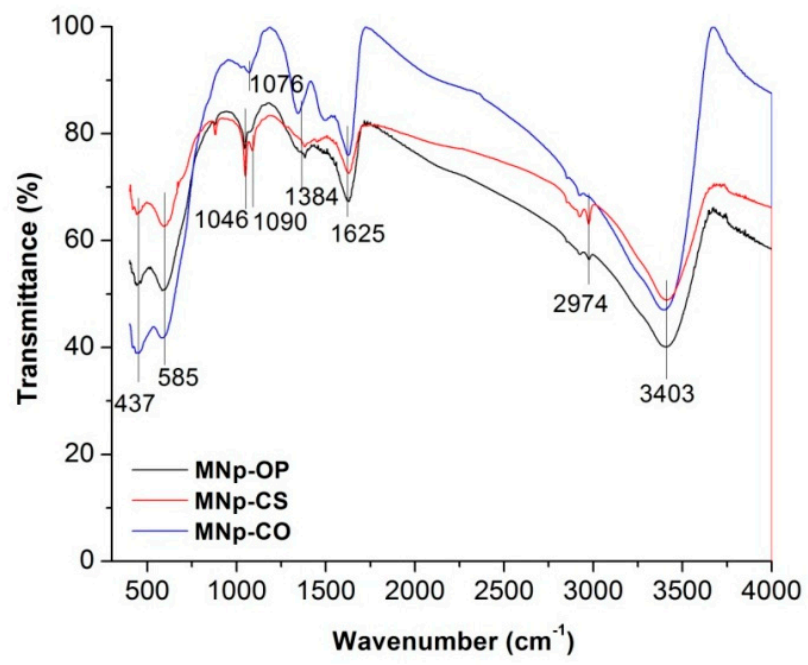

Figure 3. Fourier-transform infrared spectroscopy (FTIR) spectra of MNp-OP, MNp-CS and MNp-CO.

All spectra exhibited broad and strong bands at $3420 \mathrm{~cm}^{-1}$ and $1630 \mathrm{~cm}^{-1}$, attributable to O-H stretching and $\mathrm{O}-\mathrm{H}$ bending vibration from physisorbed water molecules [51]. The band at $2974 \mathrm{~cm}^{-1}$ is attributed to the $\mathrm{C}-\mathrm{H}$ stretching vibration of hydrocarbon chains. The peaks at 1046, 1076 and 1090 $\mathrm{cm}^{-1}$ correspond to the bending vibration of the hydroxyl groups $(\mathrm{Fe}-\mathrm{OH})$, which are responsible for the formation of inner sphere surface complexes [52]. Absorption peaks at $585 \mathrm{~cm}^{-1}$ and $437 \mathrm{~cm}^{-1}$ are characteristic peaks for magnetite confirming that green synthesis as a chemical synthesis can produce $\mathrm{Fe}_{3} \mathrm{O}_{4}$ nanoparticles $[25,36,49]$.

The textural characteristics of the synthesized magnetic nanoparticles, including specific surface area, mesopore and micropore volumes and average pore size of the synthesized sorbents, obtained by BET, BJH and model $t$-tests, are shown in Table 2.

Table 2. Characteristics of MNp-OP, MNp-CS and MNp-CO.

\begin{tabular}{|c|c|c|c|c|}
\hline Adsorbents & $\begin{array}{c}\text { Specific Surface } \\
\text { Area }\left(\mathrm{m}^{2} / \mathrm{g}\right)\end{array}$ & $\begin{array}{l}\text { Mesopore Volume } \\
\left(\mathrm{cm}^{3} / \mathrm{g}\right)\end{array}$ & $\begin{array}{c}\text { Micropore } \\
\text { Volume }\left(\mathrm{cm}^{3} / \mathrm{g}\right)\end{array}$ & $\begin{array}{l}\text { Average Pore Size } \\
\text { (nm) }\end{array}$ \\
\hline MNp-OP & 243 & 0.067 & 0.038 & 1.42 \\
\hline MNp-CS & 261 & 0.066 & 0.042 & 1.29 \\
\hline $\mathrm{MNp}-\mathrm{CO}$ & 72.1 & 0.155 & 0 & 10.5 \\
\hline
\end{tabular}

BET analysis show that the specific surface area of magnetic nanoparticles synthesized via the green method, MNp-OP and MNp-CS, have much larger specific surfaces than $\mathrm{MNp}-\mathrm{CO}$ and other structurally similar adsorbents, such as magnetite nanoparticles synthesized with plantain peel extract $\left(11.31 \mathrm{~m}^{2} / \mathrm{g}\right)$ [36], commercially available magnetite and maghemite nanoparticles (40 and $39 \mathrm{~m}^{2} / \mathrm{g}$, respectively), magnetite nanoparticles synthesized via electrical wire explosion (EWE) $\left(12 \mathrm{~m}^{2} / \mathrm{g}\right)$ [13], etc. The mesopore volume of $\mathrm{MNp}-\mathrm{CO}$ obtained by BJH method was higher than for green synthesized 
magnetic nanoparticles. However, in comparison with $\mathrm{MNp}-\mathrm{CO}$, the $t$-test method shows that $\mathrm{MNp}$-OP and MNp-CS also contain micropores ( 0.038 and $0.042 \mathrm{~cm}^{3} / \mathrm{g}$, respectively) and pore size less than 2 $\mathrm{nm}$, which means that according to the International Union of Pure and Applied Chemistry (IUPAC) classification, these materials may be considered as microporous adsorbents (pore diameter less than 2 $\mathrm{nm}$ ) [53]. The magnetite nanoparticles synthesized via conventional precipitation method, $\mathrm{MNp}-\mathrm{CO}$, do not have micropores, and its pore size was $10.5 \mathrm{~nm}$, implying a mesoporous structure of this material (pore diameter in the range 2 to $50 \mathrm{~nm}$ ).

The points of zero charge of $\mathrm{MNp}-\mathrm{OP}, \mathrm{MNp}-\mathrm{CS}$ and $\mathrm{MNp}-\mathrm{CO}$ are $\mathrm{pH}_{\mathrm{pzc}}=5.63, \mathrm{pH}_{\mathrm{pzc}}=6.75$ and $\mathrm{pH}_{\mathrm{pzc}}=6.18$, respectively (Figure 4). It is well known that at $\mathrm{pH}$ values less than $\mathrm{pH}_{\mathrm{pzc}}$, the surface of the sorbent is positively charged, which favours the sorption of negatively charged arsenic anions. In contrast, at $\mathrm{pH}$ values higher than $\mathrm{pH}_{\mathrm{pzc}}$, the surface of the sorbent is negatively charged, leading to electrostatic repulsions between the surface of the sorbent and the arsenic anion. Since the speciation of arsenic in the investigated groundwater shows that dominant form of arsenic (Table 1) was $\mathrm{As}(\mathrm{III})$, which exists in neutral form $\left(\mathrm{as}_{3} \mathrm{AsO}_{3}\right)$ at the $\mathrm{pH}$ of the groundwater $(\mathrm{pH}=8.05 \pm 0.15)$, the contribution of electrostatic interactions during adsorption of $\mathrm{As}(\mathrm{III})$ on the synthesized materials will be insignificant.

(a)

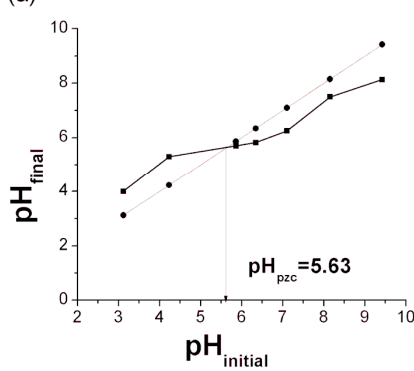

(b)

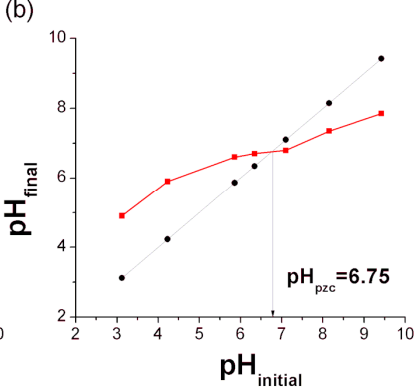

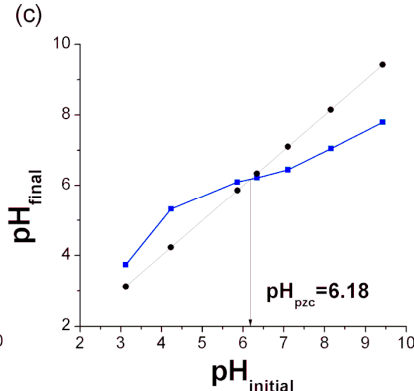

Figure 4. Points of zero charge of the synthesized (a) MNp-OP (b) MNp-CS and (c) MNp-CO.

\subsection{Formation of $M N p-O P$ and $M N p-C S$}

The antioxidant capacity of the plant extract is essential for synthesis of the magnetic nanoparticles and is usually in good correlation with phenols contents including flavonoids and tannins [54]. Their concentrations in the onion peel and corn silk extracts were therefore quantified. The results obtained from these tests are given in Table 3.

Table 3. Total phenols, flavonoids and tannins contents of onion peel and corn silk extracts.

\begin{tabular}{|c|c|c|c|c|c|}
\hline & $\begin{array}{l}\text { Total Phenols } \\
\text { (mg GAE/g dw) }\end{array}$ & $\begin{array}{l}\text { Total Flavonoids } \\
\text { (mg QE/g dw) }\end{array}$ & $\begin{array}{l}\text { Total Tannins } \\
(\mathrm{mg} \mathrm{CE} / \mathrm{g} \text { dw) }\end{array}$ & $\begin{array}{c}\mathrm{DPPH}^{\bullet} \mathrm{IC} \mathrm{C}_{50} \\
(\mu \mathrm{g} / \mathrm{mL})\end{array}$ & $\begin{array}{c}\text { FRAP } \\
(\mathrm{mg} \mathrm{TE} / \mathrm{g} \mathrm{dw})\end{array}$ \\
\hline Onion peel extract & $155 \pm 4.8$ & $19.9 \pm 1.8$ & $133 \pm 9.5$ & $8.82 \pm 0.87$ & $2.17 \pm 0.17$ \\
\hline Corn silk extract & $756 \pm 56.3$ & $205 \pm 7.1$ & $532 \pm 16$ & $2.93 \pm 0.21$ & $6.44 \pm 0.32$ \\
\hline
\end{tabular}

The corn silk extract has higher phenols, flavonoids and tannins contents than the onion peel extracts. Furthermore, the antioxidant capacity of corn silk extract obtained as DPPH ${ }^{\bullet}$ scavenging and reduction potentials were higher than the onion peel extract, confirming the close relation between the content of phytochemical compounds and the extract's antioxidant properties [55]. Lee et al. [27] investigated different conditions for the extraction of phenolic compounds including flavonoids from onion peel and observed that total phenols and total flavonoids contents for onion peel extracts produced by hot water $\left(80^{\circ} \mathrm{C}\right.$ for $3 \mathrm{~h}$ ) was $120.60 \pm 6.05 \mathrm{GAE} / \mathrm{g}$ dry weight of extract and $54.50 \pm 5.21$ $\mathrm{mg} \mathrm{QE} / \mathrm{g}$ dry weight. The total phenols and flavonoids contents in corn silk extract in our study were also found to be comparable with corn silk extracts reported by other researchers [56,57]. It is possible that the mild extract conditions applied in this work $\left(30^{\circ} \mathrm{C}\right.$ for $\left.1 \mathrm{~h}\right)$, which were chosen for their 
significantly lower energy cost, resulted in fewer losses of phenolic compounds due to oxidation [58]. In general, however, the phytochemical content of plants is greatly affected by plant variety, maturity, growing conditions, cultivar areas and harvest times, so it is also possible the relatively high phenol contents in this work are the results of natural variation [35,59].

The characterisation results presented above demonstrate that the addition of $\mathrm{FeCl}_{3}$ to the onion peel or corn silk extracts cause the reduction of $\mathrm{Fe}^{3+}$ and subsequent formation of $\mathrm{Fe}_{3} \mathrm{O}_{4}$ nanoparticles. As can be seen from extract characterization (Table 3), onion shell and corn silk extract contained different phytochemical compounds with high antioxidant activities. In the synthesis of MNp-OP (suggested mechanism shown in Figure 5), we assume that the flavonoid querecetin, the major flavonoid in the onion peel extract, plays a critical role. Initially, carbonyl and hydroxyl groups (3-hydroxo-4-ketopresent) in these molecules chelate with $\mathrm{Fe}^{3+}$ to form ferric complex [60]. This metal chelation also has pro-oxidant properties (via electron or H-atom donation), whereas the transfer of an electron to $\mathrm{Fe}^{3+}$ resulting in formation of $\mathrm{Fe}^{2+}$ where quinones are suggested as flavonoid oxidation products [60]. Finally, $\mathrm{Fe}^{2+}$ and excess $\mathrm{Fe}^{3+}$ form black precipitate of $\mathrm{Fe}_{3} \mathrm{O}_{4}$ nanoparticles. Like onion peel, corn silk extract is also rich in phenolic compounds which are capable of reducing $\mathrm{Fe}^{3+}$ [61].

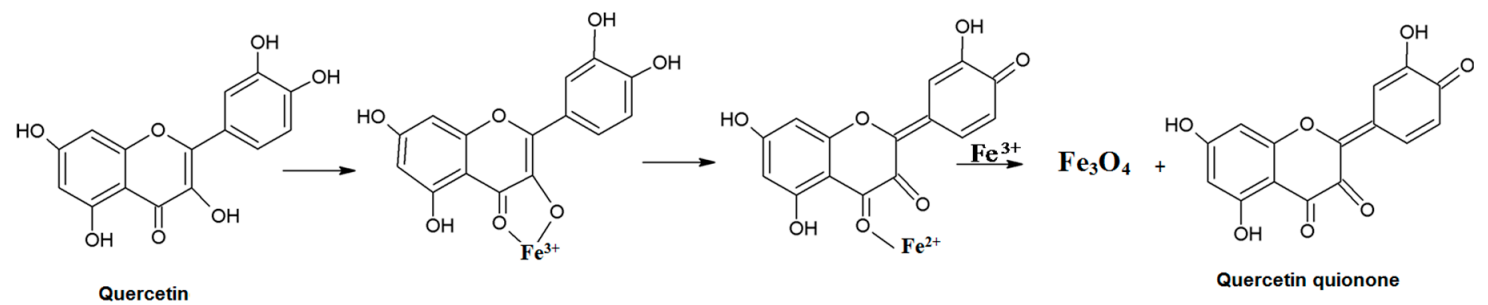

Figure 5. Schematic illustration of preparation of magnetic nanoparticles (MNp-OP) obtained from onion peel extract.

The results above demonstrate that onion peel and corn silk can both be used to produce magnetic nanoparticles, thus representing a significant added value to materials currently disposed of as a non-usable wastes.

\subsection{Arsenic Adsorption Kinetics}

Kinetic adsorption experiments and their corresponding mathematical models were used to investigate the adsorption rate and mechanism of arsenic removal on the synthesized magnetic nanoparticles. The changes in the adsorption of the synthesized nanoparticles $\left(\mathrm{q}_{\mathrm{t}}\right)$ of arsenic during time $t$, are presented in Figure 6.

(a)

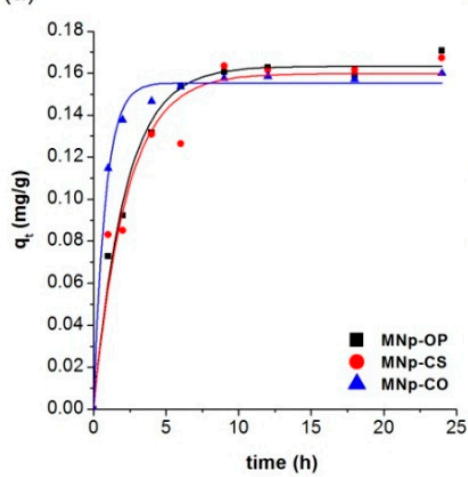

(b)

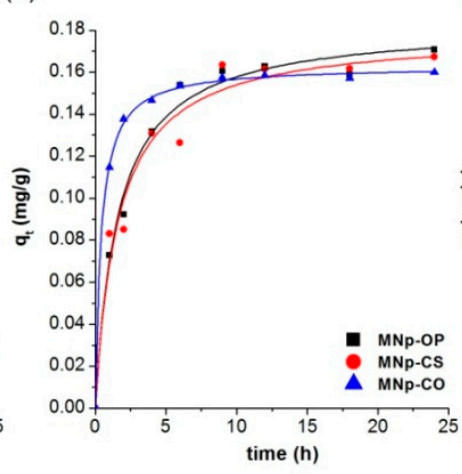

(c)

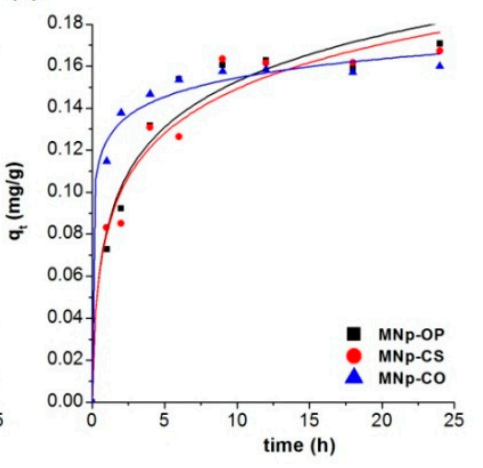

Figure 6. (a) Pseudo-first order (b) pseudo-second order and (c) Elovich model for adsorption of As on MNp-OP, MNp-CS and MNp-CO. 
As can be seen from Figure 6, the adsorption process is time dependent and can be divided into two steps. During the first $4 \mathrm{~h}$, adsorption of arsenic was fast and over this period, arsenic removal was $55-61 \%$, depending on the applied magnetic nanoparticles. In subsequent slower steps, the adsorption of arsenic decreased and reached equilibrium after $9 \mathrm{~h}$ in the case of MNp-OP and MNp-CS. In the case of arsenic adsorption on $\mathrm{MNp}-\mathrm{CO}$, a contact time of $6 \mathrm{~h}$ was sufficient to reach equilibrium.

The adsorption behaviour of arsenic on the synthesized materials can be explained by the basic mechanisms of sorption and the hydrodynamics of the system. Namely, at the beginning of the process, the number of sorption sites and the concentration of arsenic in the solution are maximum, so the driving force of the sorption process is also at a maximum. In addition, mixing provides the energy necessary to transport the arsenic through the liquid film to the active sites on the sorbent. Consequently, sorption is promoted by these three facts: the presence of a large number of active sites, a large driving force and less resistance to mass transfer caused by mixing [62]. Over time, due to the accumulation of arsenic on the sorbent surface and the resulting decrease in the concentration gradient, the rate of arsenic sorption decreases, eventually reaching a state of equilibrium.

In addition, since the equilibrium time in all investigated cases was relatively slow (in the order of hours), this suggests that specific adsorption (which involves the formation of inner surface complexes) of arsenic occurs on these materials. Unlike specific adsorption, adsorption that is achieved only by electrostatic interactions is usually very fast (in the order of seconds) [63].

To obtain more in-depth information about the mechanism of arsenic adsorption onto the synthesized magnetic nanoparticles, the kinetic data was fitted to pseudo-first-order, pseudo-second-order, and Elovich kinetic models [40]. The parameters of these models are presented in Table 4.

Table 4. Kinetic parameters for arsenic adsorption on MNp-OP, MNp-CS and MNp-CO.

\begin{tabular}{ccccc}
\hline & & MNp-OP & MNp-CS & MNp-CO \\
\hline \multirow{3}{*}{ Pseudo-first order } & $\mathrm{k}_{1}(\mathrm{1} / \mathrm{h})$ & 0.459 & 0.443 & 1.26 \\
& $\mathrm{q}_{\mathrm{e}}(\mathrm{mg} / \mathrm{g})$ & 0.164 & 0.159 & 0.155 \\
& $\mathrm{R}^{2}$ & 0.9867 & 0.9371 & 0.9925 \\
\hline \multirow{5}{*}{ Pseudo-second order } & $\mathrm{k}_{2}(\mathrm{~g} / \mathrm{mg} \mathrm{h})$ & 3.43 & 3.49 & 15.2 \\
& $\mathrm{q}_{\mathrm{e}}(\mathrm{mg} / \mathrm{g})$ & 0.183 & 0.179 & 0.163 \\
& $\mathrm{q}$ eexp $(\mathrm{mg} / \mathrm{g})$ & 0.170 & 0.173 & 0.177 \\
& $\mathrm{~h}(\mathrm{mg} / \mathrm{g} \mathrm{h})$ & 0.115 & 0.112 & 0.403 \\
& $\mathrm{R}^{2}$ & 0.9871 & 0.9632 & 0.9990 \\
\hline \multirow{2}{*}{ Elovich } & $\alpha(\mathrm{mg} / \mathrm{g} \mathrm{h})$ & 0.377 & 0.382 & 180 \\
& $\beta(\mathrm{mg} / \mathrm{g})$ & 31.3 & 32.3 & 76.6 \\
& $\mathrm{R}^{2}$ & 0.9592 & 0.9607 & 0.9868 \\
\hline
\end{tabular}

Based on the coefficients of determination $\left(R^{2}\right)$, all applied models show good fit with the experimental data. However, the highest values of $\mathrm{R}^{2}$ were observed for the pseudo-second-order kinetic model in all cases (Table 4), implying that adsorption process may be controlled by chemisorption [8]. The theoretical $\mathrm{q}_{\mathrm{e}}$ values calculated from the pseudo-second order model were very close to the experimental $\mathrm{q}_{\mathrm{e}}$ values confirming the good agreement with the model. The initial sorption rate, $\mathrm{h}$, in all cases was higher in comparison to the rate constant $k_{2}$, indicating that the rate of adsorption was much faster at the beginning of the process and decreased with time.

In a solid-liquid sorption process, which include porous adsorbents, transfer of adsorbate often takes place over four steps: bulk diffusion, film diffusion (which includes transfer of adsorbate from the bulk liquid phase to the adsorbent's external surface through a hydrodynamic boundary layer or film), intraparticle diffusion (which involves diffusion of adsorbate into the pores of the adsorbent, along pore-wall surfaces, or both), and sorption of sorbate molecules onto active sites distributed within the sorbent particles [64]. The first and last steps are usually very fast and they do not have a 
determinant role in governing sorption rates. Consequently, the adsorption rate might be controlled by external diffusion, inner diffusion or both.

Since the pseudo-first, the pseudo-second order and Elovich kinetic models cannot identify the influence of diffusion on sorption, the intraparticle diffusion model proposed by Weber and Morris, and the external diffusion model, were also used to fit the experimental data (Table 5, Figures 7 and 8).

Table 5. Intraparticle and external diffusion parameters for arsenic adsorption on MNp-OP, MNp-CS and $\mathrm{MNp}-\mathrm{CO}$.

\begin{tabular}{ccccc}
\hline Diffusion Model & Parameters & MNp-OP & MNp-CS & MNp-CO \\
\hline & $\mathrm{k}_{\mathrm{i}}\left(\mathrm{mg} / \mathrm{g} \mathrm{h}^{0.5}\right)$ & 0.0576 & 0.0407 & 0.0954 \\
& $\mathrm{C}_{\mathrm{i}}$ & 0.0139 & 0.0376 & 0.0250 \\
Weber-Morris model & $\mathrm{R}^{2}$ & 0.9630 & 0.8844 & 0.8364 \\
& $\mathrm{k}_{\mathrm{i}}\left(\mathrm{mg} / \mathrm{g} \mathrm{h}^{0.5}\right)$ & 0.00510 & 0.00188 & 0.150 \\
& $\mathrm{Ci}$ & 0.143 & 0.156 & 0.00195 \\
& $\mathrm{R}^{2}$ & 0.5454 & 0.0319 & 0.4932 \\
\hline \multirow{2}{*}{ Boyd model } & Intercept & 0.240 & 0.254 & 0.482 \\
& $\mathrm{R}^{2}$ & 0.9822 & 0.9288 & 0.9942 \\
\hline
\end{tabular}

(a)

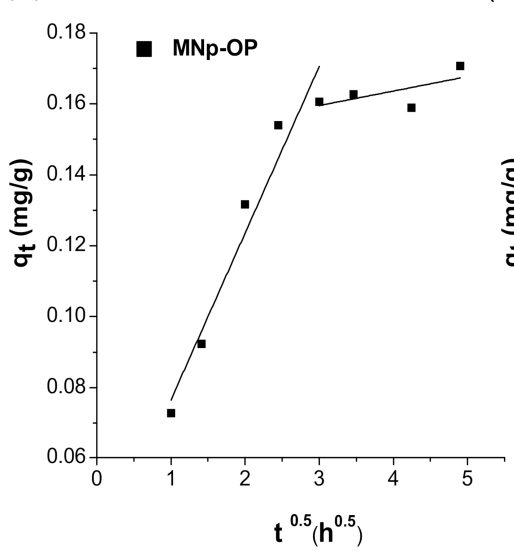

(b)

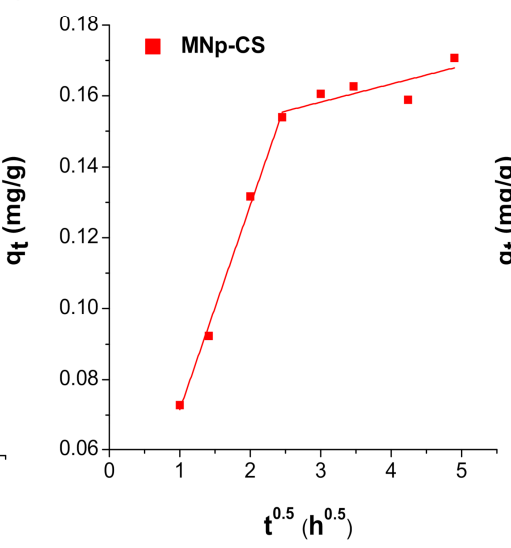

(c)

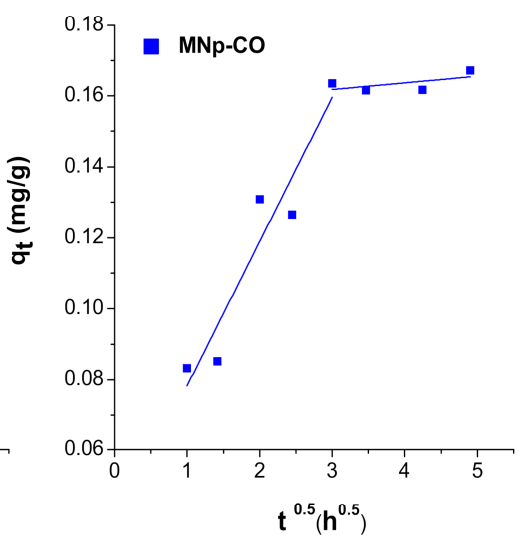

Figure 7. Weber-Morris model for arsenic adsorption on (a) MNp-OP (b) MNp-CS and (c) MNp-CO. Initial As concentration $120 \mu \mathrm{g} / \mathrm{L}$; adsorbent dose $0.5 \mathrm{~g} / \mathrm{L} ; \mathrm{pH} 8.2$.

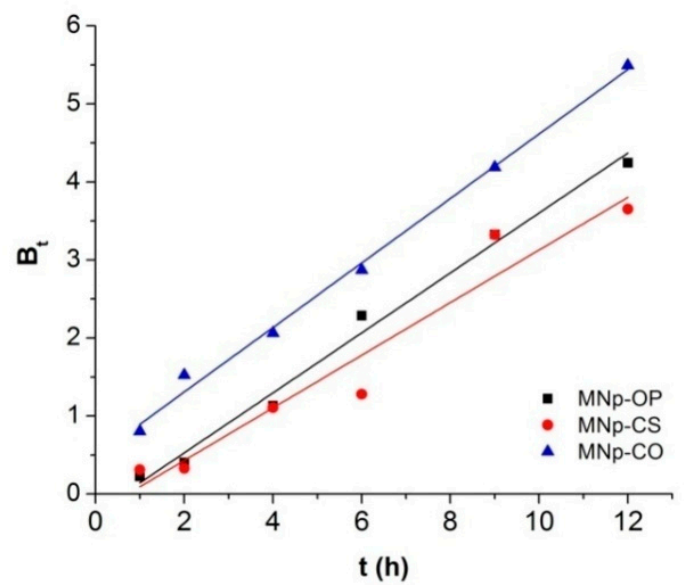

Figure 8. Boyd model for arsenic adsorption on MNp-OP, MNp-CS and MNp-CO. Initial As concentration $120 \mu \mathrm{g} / \mathrm{L}$; adsorbent dose $0.5 \mathrm{~g} / \mathrm{L}$; pH 8.2. 
According to the Weber-Morris model, if the plot of $\mathrm{q}_{\mathrm{t}} \mathrm{vs} . \mathrm{t}^{0.5}$ is linear and passes through the origin, adsorption is entirely governed by intraparticle diffusion. In contrast, if the plot is multilinear, it indicates that the adsorption is a multi-stage process controlled by various limiting factors at different steps of the process [8].

As can be seen from Figure 7 all the plots present multi-linearity, imply that intraparticle diffusion was involved in the adsorption process, but not the only rate-controlling step. Moreover, all plots give an intercept $C$ (Table 4) which means that external film mass transfer or boundary layer control also exists.

The contribution of boundary layer or film diffusion is often confirmed using the Boyd model [65]. According to this model, if the plot Bt vs. $t$, is a straight line passing through the origin, then intraparticle diffusion is the rate controlling step. Otherwise film diffusion determines the process.

From Figure 8, it is observed that all plots $t$ are linear, but the curves do not pass through the origin and have an intercept, suggesting that arsenic sorption on MNp-OP, MNp-CS and MNp-CO was mainly governed by external mass transfer (film diffusion) [66].

In order to make a distinction between kinetic and diffusion control, a very general guideline can be used: if equilibrium is achieved within $3 \mathrm{~h}$, the process is usually kinetic controlled and above $24 \mathrm{~h}$, it is diffusion-controlled [67]. Thus, taking into account that the equilibrium time of arsenic adsorption on MNp-OP, MNp-CS and MNp-CO was $6 \mathrm{~h}$ and $9 \mathrm{~h}$, respectively, the good correlation of the experimental data with the pseudo-second order model, and the results obtained by the diffusion model, we suggest that adsorption mechanism on $\mathrm{MNp}-\mathrm{OP}, \mathrm{MNp}-\mathrm{CS}$ and $\mathrm{MNp}-\mathrm{CO}$ is a complex process involving chemical interaction (surface adsorption), external and intraparticle diffusion.

\subsection{Arsenic Adsorption Isotherms}

Adsorption isotherms are fundamental in describing the interactive behaviour between adsorbate and adsorbent. The adsorption isotherm yields certain constant values, which express the surface properties and affinity of the adsorbent which play an important role in the design of an adsorption system. Different adsorption isotherms have been developed, however in this study, the non-linear form of Langmuir, Freundlich, Temkin and Dubinin-Radushkevich isotherms [41] were used to model the experimental equilibrium data (Figure 9, Table 6).

a)

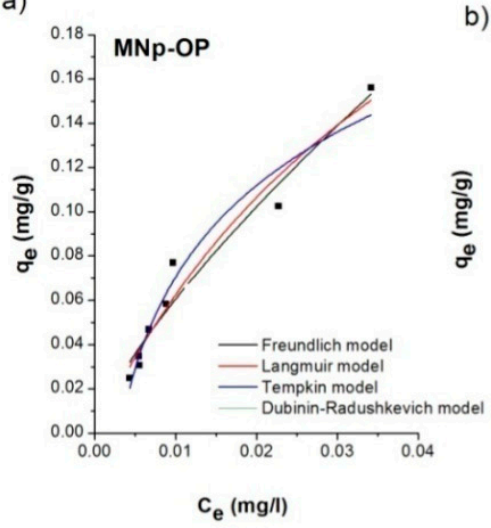

b)

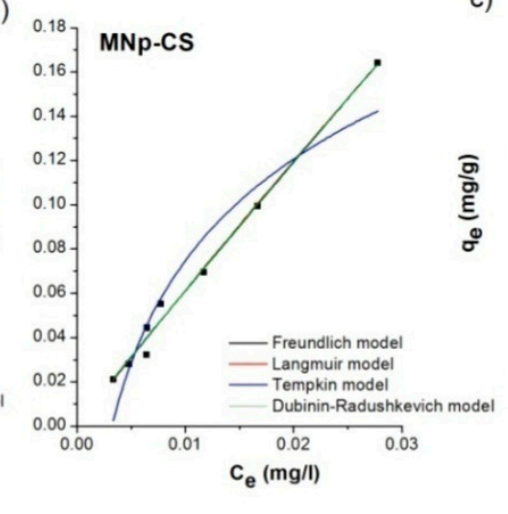

c)

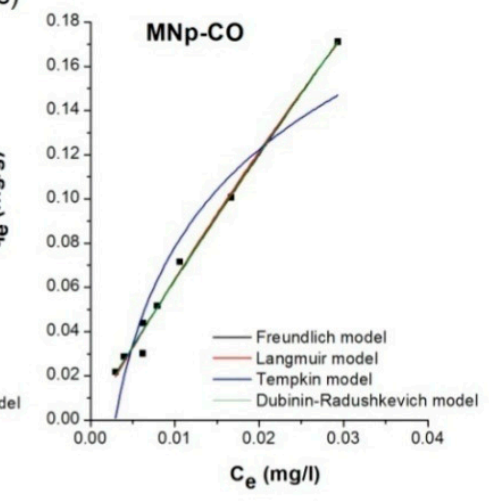

Figure 9. Adsorption isotherms of arsenic on (a) MNp-OP (b) MNp-CS and (c) MNp-CO. $\left(\mathrm{C}_{0}(\mathrm{As})=\right.$ $120 \mu \mathrm{g} / \mathrm{L}$; sorbent dose $0.5-5 \mathrm{~g} / \mathrm{L} ; \mathrm{pH}=8.1$. 
Table 6. Parameters of Freundlich, Langmuir, Temkin and Dubinin-Radushkevich sorption isotherm models for As(III) and As(V) sorption on MNp-OP, MNp-CS and MNp-CO.

\begin{tabular}{cccc}
\hline & MNp-OP & MNp-CS & MNp-CO \\
\hline Freundlich model & & & \\
$\mathrm{K}_{\mathrm{F}}(\mathrm{mg} / \mathrm{g}) /(\mathrm{mg} / \mathrm{L})^{\mathrm{n}}$ & 4.97 & 5.22 & 4.49 \\
$\mathrm{n}$ & 0.756 & 0.966 & 0.925 \\
$\mathrm{R}^{2}$ & 0.9620 & 0.9899 & 0.9901 \\
\hline Langmuir model & & & \\
$\mathrm{q}_{\max }(\mathrm{mg} / \mathrm{g})$ & 1.86 & 2.79 & 1.30 \\
$\mathrm{~K}_{\mathrm{L}}(\mathrm{L} / \mathrm{g})$ & 8.21 & 2.24 & 5.15 \\
$\mathrm{R}_{\mathrm{L}}$ & 0.9524 & 0.782 & 0.610 \\
$\mathrm{R}^{2}$ & 0.9594 & 0.9880 & 0.9881 \\
\hline Dubinin-Radushkevich model & & & \\
$\mathrm{q}_{\mathrm{d}}(\mathrm{mg} / \mathrm{g})$ & 4.45 & 5.64 & 4.84 \\
$\mathrm{k}_{\mathrm{ads}}\left(\mathrm{mol}{ }^{2} / \mathrm{kJ}{ }^{2}\right)$ & 0.000671 & 0.000397 & 0.000381 \\
$\mathrm{E}^{(\mathrm{kJ} / \mathrm{mol})}$ & 27.3 & 35.5 & 36.2 \\
$\mathrm{R}^{2}$ & 0.9473 & 0.9878 & 0.9496 \\
Tempkin model $_{\mathrm{b}_{\mathrm{T}}(\mathrm{kJ} / \mathrm{mol})}$ & & \\
$\mathrm{A}_{\mathrm{T}}(\mathrm{L} / \mathrm{g})$ & 41.2 & 37.1 & 38.6 \\
$\mathrm{R}^{2}$ & 325 & 309 & 341 \\
\hline
\end{tabular}

The results of the isotherm modelling, based on the coefficient of determination $\left(R^{2}\right)$, revealed that all applied models show good agreement with the experimental data (Table 6). However, the Freundlich model provided slightly better fit for As adsorption on MNp-OP, MNp-CS and MNp-CO (coefficients of determination, $R^{2}$, were $0.9620,0.9899$ and 0.9901 , respectively), suggesting that multilayer (heterogeneous) adsorption was the preferred removal mechanism $[51,68]$. This is supported by the SEM images, which showed that the surface of these materials was nonuniform with different particle shapes and sizes.

The Freundlich constant $\mathrm{K}_{\mathrm{f}}$ of $\mathrm{MNp}-\mathrm{CS}$ and $\mathrm{MNp}-\mathrm{OP}$ was higher than for $\mathrm{MNp}-\mathrm{CO}$, implying that the green synthesized adsorbents can be competitive in terms of adsorption affinity with magnetic nanoparticles produced via chemical precipitation method. The parameter, $1 / \mathrm{n}$ as a measure of adsorption intensity or adsorbent surface heterogeneity, in all cases was less than 1 , indicating that adsorption of As on synthesized magnetic nanoparticles is favourable and chemical in nature [68].

The maximum adsorption capacity obtained from the Langmuir model $\left(\mathrm{q}_{\max }\right)$ of the MNp-CS and MNp-OP was higher than MNp-CO. This trend was in accordance with the $\mathrm{K}_{\mathrm{F}}$ values obtained by the Freundlich model. The Langmuir equilibrium constant which reflects the affinity between adsorbent and the adsorbate, $\mathrm{K}_{\mathrm{L}}(\mathrm{L} / \mathrm{g})$, was 8.21, 2.24 and $5.15 \mathrm{~L} / \mathrm{g}$, for MNp-OP, MNp-CS and MNp-CO, respectively, suggesting strong binding of arsenic onto the magnetite nanoparticles. Separation factors $\left(\mathrm{R}_{\mathrm{L}}\right)$, essential characteristics of the Langmuir model, were in all cases below 1 , which means that adsorption of arsenic on synthesized magnetic nanoparticles was favourable [69]. This was consistent with the Freundlich constants $1 / n$ measure of sorption intensity, which also ranged between zero and one.

In the case of the Dubinin-Radushkevich model, $\mathrm{R}^{2}$ values were in the order of MNp-CS > $\mathrm{MNp}-\mathrm{CO}>\mathrm{MNp}-\mathrm{OP}$. The theoretical sorption capacity $\left(\mathrm{q}_{\mathrm{d}}\right)$ obtained from this model was the highest for $\mathrm{MNp}$-CS and the lowest for $\mathrm{MNp}-\mathrm{CO}$, which could be attributed to its higher specific surface area (Table 2). The free energy of adsorption (E) for MNp-OP, MNp-CS and MNp-CO, were $27.3 \mathrm{~kJ} / \mathrm{mol}$, $35.5 \mathrm{~kJ} / \mathrm{mol}$ and $36.2 \mathrm{~kJ} / \mathrm{mol}$, respectively, implying that chemisorption may be the preferred sorption mechanism of As on the magnetic nanoparticles. Namely, when the value of $E$ is less than $20 \mathrm{~kJ} / \mathrm{mol}$, the adsorption process is called physisorption, if it is between $20-40 \mathrm{~kJ} / \mathrm{mol}$ the process is known as ionic exchange, and when $\mathrm{E}$ is larger than $40 \mathrm{~kJ} / \mathrm{mol}$ it is a chemisorption process [70]. 
The correlation coefficients for the Tempkin isotherm were low in comparison with other applied models $\left(R^{2}=0.8825-0.9252\right)$. Temkin constants, $b_{T}$, which represent the heat of adsorption, were in the range $37.1-41.2 \mathrm{~kJ} / \mathrm{mol}$, indicating the exothermic nature of the adsorption process. The value of $\mathrm{b}_{\mathrm{T}}>8 \mathrm{~kJ} / \mathrm{mol}$ implied that the interaction between arsenic and synthesized magnetic nanoparticles was fairly strong and was not easily reversible (chemisorption) [71] which is in agreement with the results of the Dubinin-Radushkevich model. The binding constants of magnetic nanoparticles, $\mathrm{A}_{T}$ $(\mathrm{L} / \mathrm{g})$, synthesized via green method, was higher than $\mathrm{MNp}-\mathrm{CO}$, confirming their higher adsorption capacity as predicted by the Langmuir isotherm.

Note that these experiments were all carried out in real groundwater, which is naturally contaminated with arsenic. It is therefore not possible to directly compare for example the $q_{\max }$ values obtained herein with the results of other authors, as a large number of other factors can significantly affect the efficacy of adsorption processes, especially the initial arsenic concentration and the species of arsenic present, the $\mathrm{pH}$ of the water and the presence of other anions. For example, phosphate is well known to compete with arsenic in adsorption processes [18] and has a concentration 11 times higher than the arsenic concentration in this groundwater (Table 1). Furthermore, although the arsenic content of the real groundwater investigated is an order of magnitude higher than recommended, it is still an order of magnitude lower than many of the studies carried out in synthetic matrices, where the very high initial arsenic concentrations often result in correspondingly high $\mathrm{q}_{\max }$ values $[16,18,51]$. The range of values ( 1.3 to $2.8 \mathrm{mg} / \mathrm{g}$ ) obtained in this work compare very favourably with those from our previous work, in which Fe-Mn modified granular activated carbon was investigated with the same groundwater $\left(\mathrm{q}_{\max }=0.5 \mathrm{mg} / \mathrm{g}\right)$ [72], making these the most effective sorbents we have investigated to date.

Finally, in order to evaluate the stability of synthesized nanoparticles, after the adsorption experiments, the residual iron concentrations in the treated samples were determined (Table 7).

Table 7. Residual Fe concentration in groundwater samples after arsenic adsorption on MNp-OP, $\mathrm{MNp}-\mathrm{CS}$ and MNp-CO.

\begin{tabular}{ccccccccc}
\hline Sorbent Dose $(\mathrm{g} / \mathrm{L})$ & $\mathbf{0 . 5}$ & $\mathbf{1 . 0}$ & $\mathbf{1 . 5}$ & $\mathbf{2 . 0}$ & $\mathbf{2 . 5}$ & $\mathbf{3 . 5}$ & $\mathbf{4 . 0}$ & $\mathbf{5 . 0}$ \\
\hline & \multicolumn{7}{c}{ Residual Fe $(\mathrm{mg} / \mathrm{L})$} \\
\hline MNp-OP & 0.036 & 0.045 & 0.062 & 0.068 & 0.079 & 0.116 & 0.120 & 0.171 \\
MNp-CS & 0.045 & 0.065 & 0.089 & 0.078 & 0.092 & 0.134 & 0.154 & 0.168 \\
MNp-CO & 0.035 & 0.052 & 0.065 & 0.084 & 0.086 & 0.120 & 0.133 & 0.154 \\
\hline
\end{tabular}

The residual iron concentrations increased with the applied sorbent dose. For high sorbent doses (>2.5 g/L), the maximum allowable concentration (MAC) for iron in drinking water of $0.1 \mathrm{mg} / \mathrm{L}$ was exceeded. However, the MAC for arsenic was satisfied at much lower sorbent doses where residual iron concentrations were below the permissible level, suggesting that these adsorbents can be applied safety.

\section{Conclusions}

Novel magnetic nanoparticles (MNp-OP and MNp-CS) were successfully prepared via a green synthesis approach, using environmentally sound waste materials, onion peel and corn silk extract. The presence and formation of magnetic nanoparticles was confirmed by XRD and FTIR analysis while the high specific surface area and pore volume of these materials suggested they would have good performance for the removal of arsenic from groundwater. In terms of adsorption capacity, the green synthesized magnetic nanoparticles were shown to be highly competitive and effective alternatives to magnetic nanoparticles synthesized by the most common chemical precipitation method (MNp-CO). Adsorption kinetics of arsenic on MNp-OP, MNp-CS, MNp-CO were best described by the pseudo-second-order model, suggesting a chemisorption mechanism, while the Weber-Morris and Boyd model showed that external and intraparticle diffusion contributed to the overall adsorption process. The magnetic properties of these green synthesized adsorbents, which allows for their easy 
separation from water and which thus eliminates more complex and expensive separation techniques (filtration and centrifugation methods), along with their high potential for arsenic removal from groundwater, makes these materials very promising candidates for water treatment.

Author Contributions: Conceptualization, A.T. and J.A.; Investigation, J.N., M.W., M.Š. and T.M.; Methodology, J.N. and S.M.; Project administration, J.A.; Supervision, J.A.; Visualization, J.N.; Writing—original draft, J.N. and S.M.; Writing—review \& editing, A.T. and M.W.

Funding: This research was funded by the Ministry of Education, Science and Technological Development of the Republic of Serbia (Project No. TR37004 and III43005).

Acknowledgments: The authors gratefully acknowledge the support of the Ministry of Education, Science and Technological Development of the Republic of Serbia.

Conflicts of Interest: The authors declare no conflicts of interest.

\section{References}

1. Shankar, S.; Shanker, U.; Shikha. Arsenic Contamination of Groundwater: A Review of Sources, Prevalence, Health Risks, and Strategies for Mitigation. Sci. World J. 2014, 2014, 304524. [CrossRef] [PubMed]

2. Abdul, M.K.S.; Jayasingheb, S.S.; Chandanaa, E.P.S.; Jayasumanac, C.; Mangala, P.; De Silva, C.S. Arsenic and human health effects: A review. Environ. Toxicol. Pharmacol. 2015, 40, 828-846. [CrossRef] [PubMed]

3. World Health Organisation (WHO). Guidelines Drinking-Water Quality, 4th ed.; WHO: Geneva, Switzerland, 2011.

4. Nicomel, N.N.; Leus, K.; Folens, K.; De Voort, P.V.; Laing, G.D. Technologies for Arsenic Removal from Water: Current Status and Future Perspectives. Int. J. Environ. Res. Public Health 2016, 13, 62. [CrossRef] [PubMed]

5. Pathan, S.; Bose, S. Arsenic Removal Using “Green” Renewable Feedstock-Based Hydrogels: Current and Future Perspectives. ACS Omega 2018, 3, 5910-5917. [CrossRef]

6. Mukherjeea, D.; Ghosha, S.; Majumdar, S.; Annapurnaa, K. Green synthesis of $\alpha-\mathrm{Fe}_{2} \mathrm{O}_{3}$ nanoparticles for arsenic(V) remediation with a novel aspect for sludge management. J. Environ. Chem. Eng. 2016, 4, 639-650.

7. Poguberović, S.; Krčmar, D.; Maletić, S.; Kónya, Z.; Tomašević Pilipović, D.; Kerkez, Đ.; Rončević, S. Removal of $\mathrm{As}(\mathrm{III})$ and $\mathrm{Cr}(\mathrm{VI})$ from aqueous solutions using "green" zero-valent iron nanoparticles produced by oak, mulberry and cherryleaf extracts. Removal of $\mathrm{As}(\mathrm{III})$ and $\mathrm{Cr}(\mathrm{VI})$ from aqueous solutions using "green" zero-valent iron nanoparticles produced by oak, mulberry and cherryleaf extracts. Ecol. Eng. 2016, 90, 42-49.

8. Medina-Ramirez, A.; Gamero-Melo, P.; Ruiz-Camacho, B.; Minchaca-Mojica, J.I.; Romero-Toledo, R.; Gamero-Vega, K.Y. Adsorption of Aqueous As(III) in Presence of Coexisting Ions by a Green Fe-Modified W Zeolite. Water 2019, 11, 281. [CrossRef]

9. Asere, T.G.; Stevens, C.V.; Laing, G.D. Use of (modified) natural adsorbents for arsenic remediation: A review. Sci. Total Environ. 2019, 676, 706-720. [CrossRef]

10. Habuda-Stanić, M.; Nujić, M. Arsenic removal by nanoparticles: A review. Environ. Sci. Pollut. Res. 2015, 22, 8094-8123. [CrossRef]

11. Siddiqui, S.I.; Chaudhry, S.A. Arsenic removal from water using nano-composites: A review. Curr. Environ. Eng. 2017, 4, 81-102. [CrossRef]

12. Wong, W.W.; Wong, H.Y.; Borhan, A.; Badruzzaman, M.; Goh, H.H.; Zaman, M. Recent advances in exploitation of nanomaterial for arsenic removal from water: A review. Nanotechnology 2017, 28, 1-31. [CrossRef] [PubMed]

13. Song, K.; Kim, W.; Suh, C.Y.; Shin, D.; Ko, K.S.; Ha, K. Magnetic iron oxide nanoparticles prepared by electrical wire explosion for arsenic removal. Powder Technol. 2013, 246, 572-574. [CrossRef]

14. Lunge, S.; Singh, S.; Sinha, A. Magnetic iron oxide $\left(\mathrm{Fe}_{3} \mathrm{O}_{4}\right)$ nanoparticles from tea waste for arsenic removal. J. Magn. Magn. Mater. 2014, 356, 21-31. [CrossRef]

15. Roya, P.K.; Choudhury, M.R.; Ali, M.A. As (III) and As (V) Adsorption on Magnetite Nanoparticles: Adsorption Isotherms, Effect of $\mathrm{pH}$ and phosphate, and Adsorption Kinetics. Int. J. Chem. Environ. Eng. 2013, 4, 55-63.

16. Tuutijärvi, T.; Lu, J.; Sillanpää, M.; Chen, G. As(V) adsorption on maghemite nanoparticles. J. Hazard. Mater. 2009, 166, 1415-1420. [CrossRef] 
17. Haw, C.Y.; Mohamed, F.; Chia, C.H.; Radiman, S.; Zakaria, S.; Huang, N.M.; Lim, H.N. Hydrothermal synthesis of magnetite nanoparticles as MRI contrast agents. J. Ceram. Int. 2010, 36, 1417-1422. [CrossRef]

18. Lin, S.; Lu, D.; Liu, Z. Removal of arsenic contaminants with magnetic- $\mathrm{Fe}_{2} \mathrm{O}_{3}$ nanoparticles. Chem. Eng. J. 2012, 211, 46-52. [CrossRef]

19. Ebrahiminezhad, A.; Zare-Hoseinabadi, A.; Sarmah, A.K.; Taghizadeh, S.; Ghasemi, Y.; Berenjian, A. Plant-Mediated Synthesis and Applications of Iron Nanoparticles. Mol. Biotechnol. 2018, 60, 154-168. [CrossRef]

20. Latha, N.; Gowri, M. Bio synthesis and characterization of $\mathrm{Fe}_{3} \mathrm{O}_{4}$ nanoparticles using Caricaya Papaya leaves extract. Synthesis 2014, 3, 1551-1556.

21. Martínez-Cabanas, M.; López-García, M.; Barriada, J.L.; Herrero, R.; de Vicente, M.E.S. Green synthesis of iron oxide nanoparticles. Development of magnetic hybrid materials for efficient As (V) removal. Chem. Eng. J. 2016, 301, 83-91. [CrossRef]

22. Awwad, A.M.; Salem, N.M. A green and facile approach for synthesis of magnetite nanoparticles. J. Nanosci. Nanotechnol. 2012, 2, 208-213. [CrossRef]

23. Kumar, B.; Smita, K.; Cumbal, L.; Debut, A. Biogenic synthesis of iron oxide nanoparticles for 2-arylbenzimidazole fabrication. J. Saudi Chem. Soc. 2014, 18, 364-369. [CrossRef]

24. Maheswari, K.C.; Sreenivasula Reddy, P. Green Synthesis of Magnetite Nanoparticles through Leaf Extract of Azadirachta indica. J. Nanosci. Technol. 2016, 2, 189-191.

25. Venkateswarlu, S.; Yoon, M. Rapid removal of cadmium ions using green synthesized $\mathrm{Fe}_{3} \mathrm{O}_{4}$ nanoparticles capped with diethyl-4-(4 amino-5-mercapto-4H-1,2,4-triazol-3-yl) phenyl phosphonate. RSC Adv. 2015, 5, 65444-65453. [CrossRef]

26. Sharma, K.; Mahato, N.; Nile, S.H.; Lee, E.T.; Lee, Y.R.; Mahato, N.; Nile, S.H.; Lee, E.T.; Lee, Y.R. Economical and environmentally-friendly approaches for usage of onion (Allium cepa L.) waste. Food Funct. 2016, 7, 3354-3369. [CrossRef] [PubMed]

27. Lee, K.A.; Kim, K.T.; Kim, H.J.; Chung, M.S.; Chang, P.S.; Park, H.; Paik, H.D. Antioxidant Activities of Onion (Allium cepa L.) Peel Extracts Produced by Ethanol, Hot Water, and Subcritical Water Extraction. Food Sci. Biotechnol. 2014, 23, 615-621. [CrossRef]

28. Bonaccorsi, P.; Caristi, C.; Gargiulli, C.; Leuzzi, U. Flavonol glucosides in Allium species: A comparative study by means of HPLC-DAD-ESI-MS-MS. Food Chem. 2008, 107, 1668-1673. [CrossRef]

29. Benítez, V.; Mollá, E.; Martín-Cabrejas, M.A.; López-Andréu, J.F.; Downes, K.; Terry, L.A.; Esteban, R.M. Study of bioactive compound content in different onion sections. Plant Foods Hum. Nutr. 2011, 66, 48-57. [CrossRef]

30. Ifesan, B.O.T. Chemical Composition of Onion Peel (Allium cepa) and its Ability to Serve as a Preservative in Cooked Beef. Int. J. Sci. Res. Methodol. 2017, 7, 25-34.

31. Aukkanita, N.; Kemngoena, T.; Ponharna, N. Utilization of Corn Silk in Low Fat Meatballs and Its Characteristics. Procedia-Soc. Behav. Sci. 2015, 197, 1403-1410. [CrossRef]

32. Nurhanan, A.R.; Rosli, W.I.W.; Mohsin, S.S.J. Total polyphenol content and Free radical scavenging activity of Cornsilk (Zea mays hairs). Sains Malays. 2012, 41, 1217-1221.

33. Nurhanan, A.R.; Rosli, W.I.W. Nutritional compositions and antioxidative capacity of the silk obtained from immature and mature corn. J. King Saud Univ. Sci. 2014, 26, 119-127.

34. Fatima, A.; Agrawal, P.; Singh, P.P. Herbal option for diabetes: An overview. Asian Pac. J. Trop. Biomed. 2012, 2, S536-S544. [CrossRef]

35. Sarepoua, E.; Tangwongchai, R.; Suriharn, B.; Kamol, L. Influence of variety and harvest maturity on phytochemical content corn silk. Food Chem. 2015, 169, 424-429. [CrossRef] [PubMed]

36. Venkateswarlu, S.; Subba Rao, Y.; Balaji, T.; Prathima, B.; Jyothi, N.V.V. Biogenic synthesis of $\mathrm{Fe}_{3} \mathrm{O}_{4}$ magnetic nanoparticles using plantain peel extract. Mater. Lett. 2013, 100, 241-244. [CrossRef]

37. Beara, I.N.; Lesjak, M.M.; Jovin, E.D.; Balog, K.J.; Anačkov, G.T.; Orčić, D.Z.; Mimica-Dukić, N.M. Plantain (Plantago L.) species as novel sources of flavonoid antioxidants. J. Agric. Food Chem. 2009, 57, 9268-9273. [CrossRef] [PubMed]

38. Beara, I.N.; Torović, L.D.; Pintać, D.; Majkić, T.M.; Orčić, D.Z.; Mimica-Dukić, N.M.; Lesjak, M.M. Polyphenolic profile, antioxidant and neuroprotective potency of grape juices and wines from Fruška Gora region (Serbia). Int. J. Food Prop. 2018, 20, S2552-S2568. [CrossRef] 
39. Zhang, G.; Liu, H.; Qu, J.; Jefferson, W. Arsenate uptake and arsenite simultaneous sorption and oxidation by Fe-Mn binary oxides: Influence of Mn/Fe ratio. $\mathrm{pH}$. $\mathrm{Ca}^{2+}$. and humic acid. J. Colloid. Interface Sci. 2012, 366, 141-146. [CrossRef]

40. Largitte, L.; Pasquier, R. A review of the kinetics adsorption models and their application to the adsorption of lead by an activated carbon. Chem. Eng. Res. Des. 2016, 109, 495-504. [CrossRef]

41. Foo, K.Y.; Hameed, B.H. Insights into the modeling of adsorption isotherm systems. Chem. Eng. J. 2010, 156, 2-10. [CrossRef]

42. USEPA. Method 200.8: Determination of Trace Elements in Waters and Wastes by Inductively Coupled Plasma-Mass Spectrometry; Revision 5.4; USEPA: Cincinnati, OH, USA, 1994.

43. Arsenic Speciation in Urine Becomes Routine Using Agilent HPLC with 7500 Series ICP-MS; 5989-8399EN; Agilent Technologies: Santa Clara, CA, USA, 2008.

44. AWWA-APHA-WEF. Standard Methods for the Examination of Water and Wastewater, 20th ed.; American Public Health Association/American Water Works Association/Water Environment Federation: Washington, DC, USA, 2012.

45. Water Quality-Determination of Phosphorus-Ammonium Molybdate Spectrometric Method; SRPS EN ISO 6878:2008; Institute for Standardization of Serbia: Belgrade, Serbia, 2008.

46. Water Quality_Determination of Chloride-Silver Nitrate Titration with Chromate Indicator (Mors Method); SRPS ISO 9297/1:2007; Institute for Standardization of Serbia: Belgrade, Serbia, 2007.

47. Water Quality—Determination of Ammonium—Distillation and Titration Method; SRPS ISO 5664:1992; Institute for Standardization of Serbia: Belgrade, Serbia, 1992.

48. Guidelines for Determination of Total Organic Carbon (TOC) and Dissolved Organic Carbon (DOC) in Water; SRPS ISO 8245:2007; Institute for Standardization of Serbia: Belgrade Serbia, 2007.

49. Mahdavi, M.; Namvar, F.; Ahmad, B.; Rosfarizan, M. Green Biosynthesis and Characterization of Magnetic Iron Oxide $\left(\mathrm{Fe}_{3} \mathrm{O}_{4}\right)$ Nanoparticles Using Seaweed (Sargassum muticum) Aqueous Extract. Molecules 2013, 18, 5954-5964. [CrossRef] [PubMed]

50. Scherrer, P. Bestimmung der Grosse und der Inneren Struktur von Kolloidteilchen Mittels Rontgenstrahlen, Nachrichten von der Gesellschaft der Wissenschaften, Gottingen. Math.-Phys. Kl. 1918, 2, 98-100.

51. Wen, Z.; Dai, C.; Zhu, Y.; Zhang, Y. Synthesis of ordered mesoporous iron manganese bimetal oxides for arsenic removal from aqueous solutions. RSC Adv. 2015, 5, 4058-4068. [CrossRef]

52. Kong, S.; Wang, Y.; Zhan, H.; Yuan, S.; Yu, M.; Liu, M. Adsorption/Oxidation of Arsenic in Groundwater by Nanoscale Fe-Mn Binary Oxides Loaded on Zeolite. Water Environ. Res. 2014, 86, 147-155. [CrossRef] [PubMed]

53. Sing, K.S.W.; Evertt, D.H.; Haul, R.A.W.; Moscou, L.R.A.; Pierotti, J.; Rouquerol, T.; Siemieniewska, T. Reporting Physisorption Data for Gas/Solid Systems with Special Reference to the Determination of Surface Area and Porosity. Pure Appl. Chem. 1985, 57, 603-619. [CrossRef]

54. Ignat, I.; Volf, I.; Popa, V.I. A critical review of methods for characterisation of polyphenolic compounds in fruits and vegetables. Food Chem. 2011, 126, 1821-3185. [CrossRef]

55. Machado, S.; Pinto, S.L.; Grosso, J.P.; Nouws, H.P.A.; Albergaria, J.T.; Delerue-Matos, C. Green production of zero-valent iron nanoparticles using tree leaf extracts. Sci. Total Environ. 2013, 445-446, 1-8. [CrossRef]

56. Nurhanan, A.R.; WR, W.I. Evaluation of polyphenol content and antioxidant activities of some selected organic and aqueous extracts of cornsilk (Zea mays hairs). J. Med Bioeng. 2012, 1, 48-51.

57. Irawaty, W.; Ayucitra, A.; Indraswati, N. Radical scavenging activity of various extracts and varieties of corn silk. ARPN J. Eng. Appl. Sci. 2018, 13, 10-16.

58. Viera, V.B.; Piovesan, N.; Rodrigues, J.B.; Mello, R.O.; Prestes, R.C.; Santos, R.C.V.; Vaucher, R.A.; Hautrive, T.P.; Kubota, E.H. Extraction of phenolic compounds and evaluation of the antioxidant and antimicrobial capacity of red onion skin (Allium cepa L.). Int. Food Res. J. 2017, 24, 990-999.

59. El Amrani, F.B.; Perello, L.; Real, J.A.; Gonzalez-Alvarez, M.; Alzuet, G.; Borras, J.; Garcia-Granda, S.; Montejo-Bernardo, J. Oxidative DNA cleavage induced by an iron(III) flavonoid complex: Synthesis, crystal structure and characterization of chlorobis (flavonolato)(methanol) iron(III) complex. J. Inorg. Biochem. 2006, 100, 1208-1218. [CrossRef] [PubMed]

60. Xu, G.R.; In, M.Y.; Yuan, Y.; Joon Lee, J.; Kim, S. In situ Spectroelectrochemical Study of Quercetin Oxidation and Complexation with Metal Ions in Acidic Solutions. Bull. Korean Chem. Soc. 2007, 28, 889-892. 
61. Ebrahimzadeh, M.A.; Pourmorad, F.; Bekhradnia, A.R. Iron chelating activity, phenol and flavonoid content of some medicinal plants from Iran. Afr. J. Biotechnol. 2008, 7, 3188-3192.

62. Mondal, P.; Mohanty, B.; Majumder, C.B. Removal of Arsenic from Simulated Groundwater by GAC-Fe: A Modeling Approach. AIChE J. 2009, 55, 1860-1871. [CrossRef]

63. Zhang, G.; Liu, H.; Liu, R.; Qu, J. Adsorption behavior and mechanism of arsenate at Fe-Mn binary oxide/water interface. J. Hazard. Mater. 2009, 168, 820-825. [CrossRef]

64. Tran, H.N.; You, S.J.; Bandegharaei, A.H.; Chao, H.P. Mistakes and inconsistencies regarding adsorption of contaminants from aqueous solutions: A critical review. Water Res. 2017, 120, 88-116. [CrossRef]

65. Boyd, G.E.; Schubert, J.; Adamson, A.W. The exchange adsorption of ions from aqueous solutions by organic zeolites. Ion-exchange equilibria. J. Am. Chem. Soc. 1947, 69, 2818-2829. [CrossRef]

66. Kajjumba, S.W.; Emik, S.; Öngen, A.; Özcan, H.K.; Aydın, S. Modelling of Adsorption Kinetic Processes-Errors, Theory and Application. In Advanced Sorption Process Applications; Edebali, S., Ed.; IntechOpen: Rijeka, Croatia, 2018.

67. Ho, Y.S.; Ng, J.C.Y.; McKay, G. Kinetics of pollutant sorption by biosorbents: Review. Sep. Purif. Method 2000, 29, 189-232. [CrossRef]

68. Niazi, N.K.; Bibi, I.; Shahid, M.; Ok, Y.S.; Burton, E.D.; Wang, H.; Shaheen, S.M.; Rinklebe, J.; Lüttge, A. Arsenic removal by perilla leaf biochar in aqueous solutions and groundwater: An integrated spectroscopic and microscopic examination. Environ. Pollut. 2018, 232, 31-41. [CrossRef]

69. Mudzielwana, R.; Gitari, M.W.; Ndungu, P. Uptake of As(V) from Groundwater Using Fe-Mn Oxides Modified Kaolin Clay: Physicochemical Characterization and Adsorption Data Modeling. Water 2019, 11, 1245. [CrossRef]

70. Monárrez-Corderoa, B.E.; Amézaga-Madrida, P.; Leyva-Porrasa, C.C.; Pizá-Ruiza, P.; Miki-Yoshidaa, M. Study of the Adsorption of Arsenic (III and V) by Magnetite Nanoparticles Synthesized via AACVD. Mater. Res. 2016, 19, 1-10.

71. Shafique, U.; Ijaz, A.; Salman, M.; Zaman, W.; Jamil, N.; Rehman, R.; Javaid, A. Removal of arsenic from water using pine leaves. J. Taiwan Inst. Chem. Eng. 2012, 43, 256-263. [CrossRef]

72. Nikić, J.; Agbaba, J.; Watson, M.A.; Tubić, A.; Šolić, M.; Maletić, S.; Dalmacija, B. Arsenic adsorption on Fe-Mn modified granular activated carbon (GAC-FeMn): Batch and fixed-bed column studies. J. Environ. Sci. Health Part A 2019, 54, 168-178. [CrossRef] [PubMed] 